\title{
Two fungal flavonoid-specific glucosidases/rutinosidases for rutin hydrolysis and rutinoside synthesis under homogeneous and heterogeneous reaction conditions
}

\author{
Michael Kotik ${ }^{1 *}$ (D, Hana Javưrková ${ }^{1}$, Katerina Brodsky ${ }^{1,2}$ and Helena Pelantová ${ }^{1}$
}

\begin{abstract}
The glycosidases within GH5-23 cleave the glycosidic bond of $\beta$-glucosylated or rutinosylated flavonoids. Moreover, by virtue of their transglycosylation activity, glycoconjugates with glucosyl and rutinosyl moieties are accessible. Here we report the biochemical characterization and biotechnological assessment of two heterologously expressed members of GH5-23-McGlc from Mucor circinelloides and PcGlc from Penicillium chrysogenum. Both enzymes exhibited the highest hydrolytic activities with quercetin-3- $\beta$-O-glucopyranoside, whereas lower specificity constants were determined with the rutinosides narcissin, rutin and hesperidin. High stabilities against thermal, ethanol and dimethyl sulfoxide-induced inactivation, a very limited secondary hydrolysis of the formed transglycosylation products, and no detectable product inhibition were additional features appropriate for biotechnological applications. The enzymes were compared in their efficiencies to hydrolyze rutin and to synthesize 2-phenylethyl rutinoside under homogeneous and heterogeneous reaction conditions using high rutin concentrations of 100 and $300 \mathrm{mM}$. Highest transglycosylation efficiencies were achieved with fully dissolved rutin in reaction mixtures containing $25 \%$ dimethyl sulfoxide. Molecular docking and multiple sequence alignments suggest that the hydrophobic environment of aromatic residues within the +1 subsite of GH5-23 glycosidases is very important for the binding of flavonoid glucosides and rutinosides.
\end{abstract}

Keywords: Transglycosylation, Flavonoid glycoside, Solubility, Dimethyl sulfoxide, Process optimization, Enzyme stability

\section{Keypoints}

Efficient transglycosylation with dissolved rutin in $25 \%$ dimethyl sulfoxide

Transglycosylations in solution are preferable to suspension-based reactions

Advantageous kinetic features of $M c$ Glc and PcGlc linked to their +1 subsites

*Correspondence: kotik@biomed.cas.cz

${ }^{1}$ Institute of Microbiology of the Czech Academy of Sciences, Vídeňská

1083, 14220 Prague 4, Czech Republic

Full list of author information is available at the end of the article

\section{Introduction}

The synthesis of both unnatural and naturally occurring glycoconjugates is of high importance in many research fields. Their chemical synthesis can be a difficult and time-consuming undertaking due to the lack of highly efficient regio- and stereoselective reagents (Desmet et al. 2012). This manifests itself in lengthy multi-step reactions, requiring protection and de-protection strategies, which often lead to unsatisfactory yields and the formation of waste products (Sheldon 2016). In this respect, retaining glycosidases with their transglycosylation activities are an alternative to chemical methods for the 
synthesis of tailored carbohydrates (Rather and Mishra 2013; Slámová et al. 2018).

Glycosylation of small molecules, e.g., quercetin, is a common strategy of nature to modify the physicochemical and biochemical properties of these compounds (Desmet et al. 2012). In order to explore the biological activities and interactions of natural and novel glycosylated compounds, their efficient synthesis is highly important for the development of probes, standards and therapeutics.

The members of the glycoside hydrolase family 5-23 (GH5-23) belong to the diverse group of diglycosidases, which accept diglycosides such as $\mathbf{2 - 5}$ as substrates (Fig. 1) (Koseki et al. 2018; Baglioni et al. 2021). So far, two out of six characterized GH5-23 enzymes have been shown to catalyze the hydrolysis of both flavonoid glucosides (e.g., 1) and flavonoid rutinosides (e.g., 2) (Pachl et al. 2020; Makabe et al. 2021). Hence, these broadspecificity enzymes can be classified as $\beta$-glucosidases or $\beta$-rutinosidases (6-O- $\alpha$-L-rhamnopyranosyl- $\beta$-Dglucopyranosidases) depending on their substrate preference. The potential applications of these enzymes are twofold. Their hydrolytic activities can be used for the production of rutinose (6-O- $\alpha$-L-rhamnosyl-D-glucose) and the aglycones quercetin or hesperetin from 2 or 3 , respectively. The hydrolysis products have applications as nutraceuticals and dietary supplements and potentially also in cosmetics (Kiso et al. 2015; Testai and Calderone 2017; Zhang et al. 2018). The synthetic or transglycosylation activities of these enzymes can be used for the synthesis of many novel rutinosylated or glucosylated compounds, including glucosyl and rutinosyl azide (Katayama et al. 2013; Šimčíková et al. 2015; Mazzaferro et al. 2019; Brodsky et al. 2020; Karnišová Potocká et al. 2021; Kotik et al. 2021).

Substantial amounts of rutinosylated flavonoids such as $\mathbf{2}$ or $\mathbf{3}$ occur in various plants and their fruits or seedpods (Lucci and Mazafera 2009; O'Shea et al. 2012; Williamson 2017), which are convenient natural sources for the commercialization of $\mathbf{2}$ and $\mathbf{3}$ as nutritional supplements (Gullon et al. 2017). Thus, 2 and 3 may be considered readily available and inexpensive glycosyl donors for enzymatic glycosylation reactions. However, their very low water solubility is problematic and poses a challenge for efficient enzymatic hydrolyses/transglycosylations.

In this work, we biochemically characterized two recombinant members of GH5-23, McGlc from Mucor circinelloides and PcGlc from Penicillium chrysogenum, with regard to their use as biocatalysts in hydrolytic and transglycosylation reactions. Both enzymes were shown to be flavonoid-specific glucanases/rutinosidases with their highest activities towards isoquercitrin. The enzymes exhibited good activities with flavonoid rutinosides, allowing their use in hydrolyses and transglycosylations under homogeneous and heterogeneous reaction conditions with $\mathbf{2}$ as a substrate and glycosyl donor. We observed complete hydrolysis of 2 in suspensions with 2 at concentrations of $0.3 \mathrm{M}$. Regarding transglycosylations, we demonstrated that reaction conditions of fully dissolved 2 in the presence of $25 \%$ dimethyl sulfoxide (DMSO) were superior to heterogeneous reaction conditions in terms of yield and process performance data. The present study unveiled the potential of DMSO-tolerant $M c$ Glc and $P c$ Glc for efficient synthetic applications in DMSO-based reaction mixtures with scarcely watersoluble $\mathbf{2}$ as an inexpensive, readily available and natural glycosyl donor.

\section{Materials and methods Chemicals}

Rutin (quercetin 3-O-rutinoside) (2) was purchased from Alchimica s.r.o. (Czech Republic). Hesperidin (hesperetin 7-O-rutinoside) (3), narcissin (isorhamnetin 3-O-rutinoside) (4), diosmin (diosmetin 7-O-rutinoside) (5), and $p$-nitrophenyl $\beta$-D-glucoside (7) were purchased from Sigma-Aldrich. Isoquercitrin (quercetin 3-O- $\beta$-Dglucopyranoside) (1) and $p$-nitrophenyl rutinoside (8) were prepared as previously described (Weignerová et al. 2012; Šimčíková et al. 2015).

\section{Expression and purification of recombinant McGlc and PcGlc}

During cultivation of the recombinant Pichia pastoris $\mathrm{KM} 71 \mathrm{H}$ strains, McGlc and PcGlc were secreted to the culture medium (Kotik et al. 2021). PcGlc was purified by cation exchange chromatography as described in Kotik et al. (2021). McGlc was purified using a Ni Sepharose column (5-ml HisTrap HP, ÄKTA 900 FPLC system; GE Healthcare Life Sciences) equilibrated with binding buffer $(20 \mathrm{mM}$ phosphate, $500 \mathrm{mM} \mathrm{NaCl}, 20 \mathrm{mM}$ imidazole, $\mathrm{pH}$ 7.4). The enzyme was eluted with a linear gradient of imidazole (500 $\mathrm{mM}$ final concentration) using a flow rate of $3 \mathrm{ml} \mathrm{min}^{-1}$ and a gradient time of $40 \mathrm{~min}$. The purified proteins were concentrated using Amicon Ultra- 0.5 and Ultra- 15 centrifugal filters $(10 \mathrm{kDa}$ cutoff; Merck KGaA, Germany). Protein concentrations were determined using a Qubit protein assay kit with a Qubit fluorometer (Life Technologies, USA). McGlc and PcGlc were analyzed for the presence of posttranslationally attached carbohydrates using a kit for glycoprotein staining (Pierce - ThermoFisher Scientific).

\section{Enzymatic reactions}

All activity determinations were performed with purified enzymes. Hydrolytic rates with substrates 1-5 were 


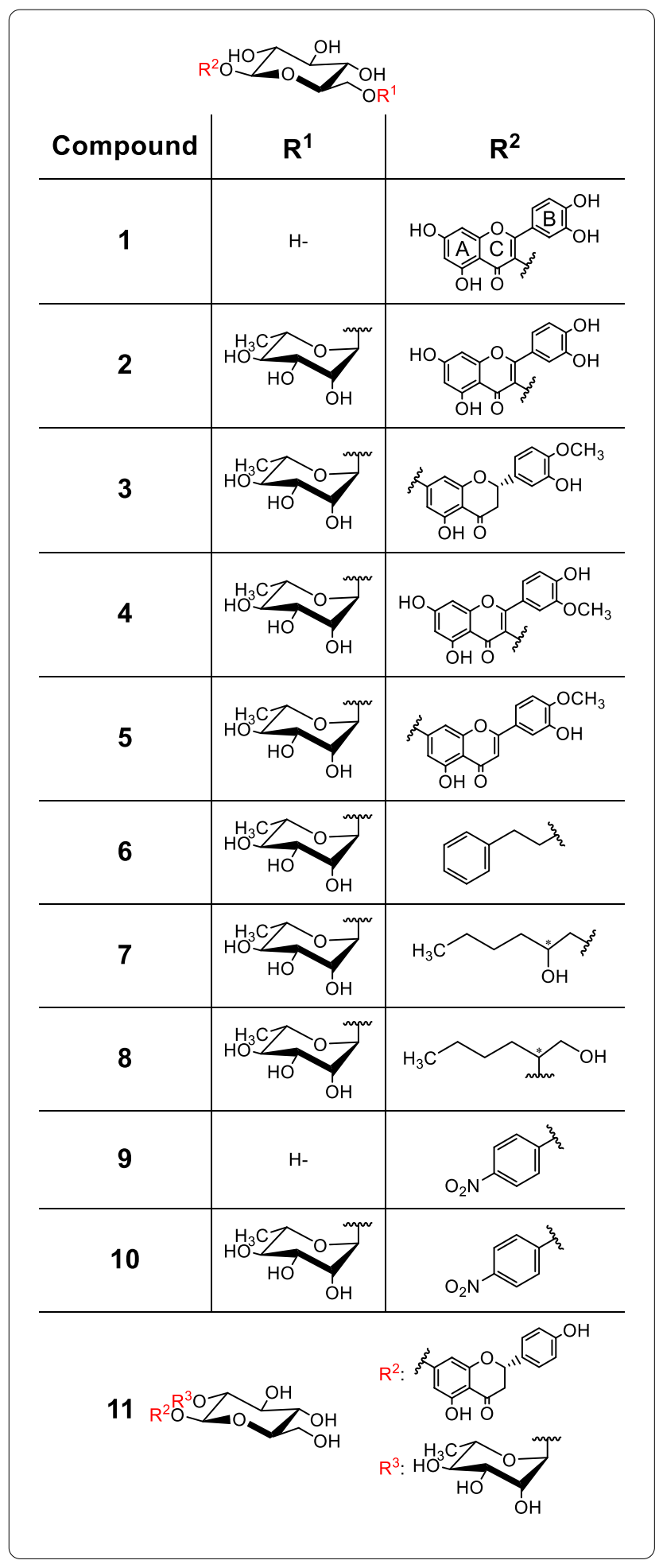

determined in $50 \mathrm{mM}$ citrate buffers in the presence of $10 \%(\mathrm{v} / \mathrm{v})$ DMSO. The reaction mixtures were incubated for 10-15 min, after which the enzyme was inactivated at $95{ }^{\circ} \mathrm{C}$ for 30 min. One unit (U) of $M c$ Glc or PcGlc-based
Fig. 1 Chemical structures of selected transglycosylation products and flavonoid glycosides tested as substrates. $\mathbf{1}$ : isoquercitrin (quercetin 3-O- $\beta$-D-glucopyranoside); 2 : rutin (quercetin 3-O-rutinoside); $\mathbf{3}$ : hesperidin (hesperetin 7-O-rutinoside); $\mathbf{4}$ : narcissin (isorhamnetin 3-O-rutinoside); $\mathbf{5}$ : diosmin (diosmetin 7-O-rutinoside); 6: 2-phenylethyl rutinoside; 7: hexane-2-ol-1-yl rutinoside; 8: hexane-1-ol-2-yl rutinoside; 9 : $p$-nitrophenyl $\beta$-D-glucoside; 10: $p$-nitrophenyl rutinoside; 11: naringin (naringenin 7-O-neohesperidoside)

activity was defined as the amount of enzyme needed for the release of $1 \mu \mathrm{mol}$ of quercetin per min using 2 as a substrate $(2.0 \mathrm{mM})$ at optimal $\mathrm{pH}$ and $48^{\circ} \mathrm{C}$. Compounds 1-6 and the released aglycones were quantified by HPLC using the appropriate calibration curves and dilutions in DMSO (see Additional file 1: Table S1 for the retention times and the detection wavelengths). HPLC was performed using a Prominence LC-20AB system (Shimadzu, Japan) at $30{ }^{\circ} \mathrm{C}$ as described by Šimčíková et al. (2015) with slightly modified gradients: $0-3 \mathrm{~min}, 7-30 \%$ B; 3-5 min, 30\% B; 5-7 min, 30-7\% B; 7-7.5 min, 7\% B. Mobile phase A: $\mathrm{CH}_{3} \mathrm{CN} / \mathrm{H}_{2} \mathrm{O} / \mathrm{HCO}_{2} \mathrm{H}(5: 95: 0.1 ; \mathrm{v} / \mathrm{v} / \mathrm{v})$; mobile phase $\mathrm{B}: \mathrm{CH}_{3} \mathrm{CN} / \mathrm{H}_{2} \mathrm{O} / \mathrm{HCO}_{2} \mathrm{H}(80: 20: 0.1 ; \mathrm{v} / \mathrm{v} / \mathrm{v})$. The reactions were also monitored by thin-layer chromatography as described by Mazzaferro et al. (2019) and Kotik et al. (2021). For transglycosylations, a 200$\mu \mathrm{L}$ reaction in the absence or presence of DMSO (10 or $25 \%$ ) was initiated at $35^{\circ} \mathrm{C}$ in Mcllvaine buffer $(\mathrm{pH} 4.5$ for $\mathrm{McGlc}$ or $\mathrm{pH} 5.0$ for PcGlc) for each data point. Preparative scale conversions with $2(5.0 \mathrm{mmol})$ as the glycosyl donor and 2-phenylethanol or 1,2-hexanediol ( $25 \mathrm{mmol})$ as the acceptor were performed overnight at $30^{\circ} \mathrm{C}$ on a $15-\mathrm{mL}$ scale with purified $\mathrm{McGlc}$ or PcGlc $(2.3 \mathrm{mg})$. The rutinosides 6 and 7/8 were purified as described in Brodsky et al. (2020) using a Biogel P2 Fine column (Bio-Rad).

\section{Effect of $\mathrm{pH}$, temperature and DMSO on enzymatic activities}

The $\mathrm{pH}$ dependence of the hydrolytic activities of $M c \mathrm{Glc}$ and PcGlc was determined in $50 \mathrm{mM}$ citrate buffers, incubating the samples without substrate at $35{ }^{\circ} \mathrm{C}$ for $30 \mathrm{~min}$, and then at $48{ }^{\circ} \mathrm{C}$ for $15 \mathrm{~min}$ in the presence of $2.7 \mathrm{mM} 2$ and $10 \%(\mathrm{v} / \mathrm{v})$ DMSO. The temperature optima for the hydrolysis of 2 were determined at $\mathrm{pH} 3.5$ for $M c$ Glc and pH 5.0 for PcGlc in the presence of $10 \%(\mathrm{v} / \mathrm{v})$ DMSO. The thermal stabilities were assessed by determining the residual hydrolytic activities after a 10 -min incubation at a given temperature at $\mathrm{pH} 4.0$ or 5.0 for $M c$ Glc or PcGlc, respectively. The effect of DMSO or ethanol on the hydrolytic activities of both enzymes was determined by varying the co-solvent concentrations in the range of $0-70 \%(\mathrm{v} / \mathrm{v})$, respectively. 


\section{Structure determination}

NMR spectra were recorded on a Bruker Avance III $400 \mathrm{MHz}$ (399.87 MHz for ${ }^{1} \mathrm{H}, 100.55 \mathrm{MHz}$ for ${ }^{13} \mathrm{C}$, $\left.\mathrm{D}_{2} \mathrm{O}, 30{ }^{\circ} \mathrm{C}, 6\right)$ and a Bruker Avance III $700 \mathrm{MHz}$ spectrometer $\left(700.13 \mathrm{MHz}\right.$ for ${ }^{1} \mathrm{H}, 176.05 \mathrm{MHz}$ for ${ }^{13} \mathrm{C}, \mathrm{D}_{2} \mathrm{O}$ and $\left.\operatorname{MeOD}(9: 1[\mathrm{v} / \mathrm{v}]), 30{ }^{\circ} \mathrm{C}, 7 / 8\right)$. The residual signal of water was used as an internal standard $\left(\delta_{\mathrm{H}} 4.732 \mathrm{ppm}\right)$; carbon chemical shifts were referenced to acetone $\left(\delta_{C}\right.$ $30.50 \mathrm{ppm})$. The following NMR experiments were performed using the manufacturer's software: COSY, ${ }^{1} \mathrm{H}$ ${ }^{13} \mathrm{C}$ HSQC, HSQC-TOCSY, $1 \mathrm{D}-\mathrm{TOCSY}$ and ${ }^{1} \mathrm{H}_{-}{ }^{13} \mathrm{C}$ HMBC. Mass spectra were recorded with a Shimadzu Prominence LC analytical system (Shimadzu, Japan) as described previously (Kotik et al. 2021).

\section{Bioinformatics}

Multiple sequence alignments were performed using CLUSTALW (Thompson et al. 1994). Homology models of $M c$ Glc and PcGlc were built using the automated modeling server SWISS-MODEL (Waterhouse et al. 2018) with the X-ray structure data of $A n$ Rut (rutinosidase from Aspergillus niger; Pachl et al. 2020) as a template (Protein Data Bank accession code 6I1A). Molecular docking was conducted using the program VINA (Trott and Olson 2010), which was implemented in the software YASARA using default settings (Krieger and Vriend 2014).

\section{Results}

\section{Conserved aromatic residues in +1 subsite}

Sequence identities of 56 and 60\% were determined between $A n$ Rut, whose X-ray structure had been determined (Pachl et al. 2020), and McGlc and PcGlc, respectively; this allowed automated structure model building with high quality estimates (Benkert et al. 2011). The superposition of the $A n$ Rut structure and the generated models of $M c$ Glc and PcGlc revealed a very high degree of structural similarity of the backbone chains of the three enzymes (Additional file 1: Fig. S1). Furthermore, a sequence alignment of $A n$ Rut, $M c$ Glc and PcGlc enabled us to predict the two key catalytic residues - the acid/ base catalyst and the catalytic nucleophile (Additional file 1: Fig. S1). Molecular docking of substrate 1 or 2 to the active site of $A n$ Rut resulted in very similar binding poses with the quercetin moieties being clamped by four aromatic side chains, comprising Phe and Tyr, located in the +1 subsite (Fig. 2). The analysis of the interactions between quercetin and the side chains in the +1 subsite indicated that predominantly hydrophobic and $\pi-\pi$ interactions were responsible for the binding of the aglycone to the +1 subsite (Additional file 1: Tables S2S5; Fig. S2). Interestingly, these four aromatic side chains in $A n$ Rut were found conserved in a multiple sequence alignment with other GH5-23 member enzymes, including McGlc and PcGlc (Fig. 2).

\section{Production of recombinant enzymes}

Typical volumetric productivities of 4-d long cultivations in BMM medium using baffled flasks were 2.2-2.4 $\mathrm{U} \mathrm{mL} \mathrm{m}^{-1} \mathrm{~d}^{-1}$. Typical purification yields for $M c$ Glc and PcGlc were 30-45 and 50\%, respectively. During purification, the specific activity of McGlc for the hydrolysis of 2 increased from 26 to $30 \mu \mathrm{mol} \mathrm{min}{ }^{-1} \mathrm{mg}^{-1}$, the corre-

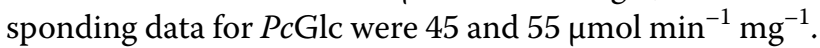

\section{Biochemical properties}

The presence of glycan chains attached to heterologously produced and purified McGlc and PcGlc was clearly detected using a sugar-specific staining method based on periodic acid and the Schiff reagent (Additional file 1: Fig. S3). The purified enzymes were further characterized in terms of their $\mathrm{pH}$ optima and stabilities. The optimal $\mathrm{pH}$ of $\mathrm{McGlc}$ for the hydrolysis of $\mathbf{2}$ was determined between 3.5 and 4.0. PcGlc exhibited a shift in the activity-pH relationship towards less acidic conditions; the optimal $\mathrm{pH}$ was determined between 5.0-5.5 (Additional file 1: Fig. S4). The maximal hydrolytic activities were determined at 55 and $60{ }^{\circ} \mathrm{C}$ for McGlc and PcGlc at their optimal pH values, respectively (Additional file 1: Fig. S5). After $10 \mathrm{~min}$ of incubation in the absence of substrate, the enzymes retained $>90 \%$ of their initial activities in the temperature range of $20-55^{\circ} \mathrm{C}$ (Additional file 1: Fig. S6). As DMSO can be used for solubilizing flavonoids in reaction mixtures, we determined its influence on the enzymatic activities. It turned out that both enzymes showed a high degree of tolerance towards this solubilizing agent with activity losses being observed only above 30-35\% (Fig. 3). Low concentrations of ethanol resulted in higher initial velocities of hydrolysis, whereas concentrations of $>20$ and $>30 \%$ led to a decrease in activity for $\mathrm{McGlc}$ and PcGlc, respectively (Fig. 3).

\section{Hydrolysis in solution - substrate specificities}

The substrate specificities of McGlc and PcGlc were determined with a range of potential substrates: 1 , which is a flavonol glucoside, and four flavonoid rutinosides (25) (Fig. 1). With the exception of 5 (Additional file 1: Fig. S7), classical Michaelis-Menten kinetics was observed with both enzymes for compounds 1-4 (Additional file 1: Fig. S8-S11). Regarding the specificity constants $k_{\mathrm{cat}} / K_{\mathrm{M}}$ (Table 1), the best substrate by far was glucoside 1 . The following substrate order - from best to worst - was determined for both $M c$ Glc and PcGlc: $1>4>2>3$. Neither $M c$ Glc nor PcGlc exhibited activities towards compound 11. 

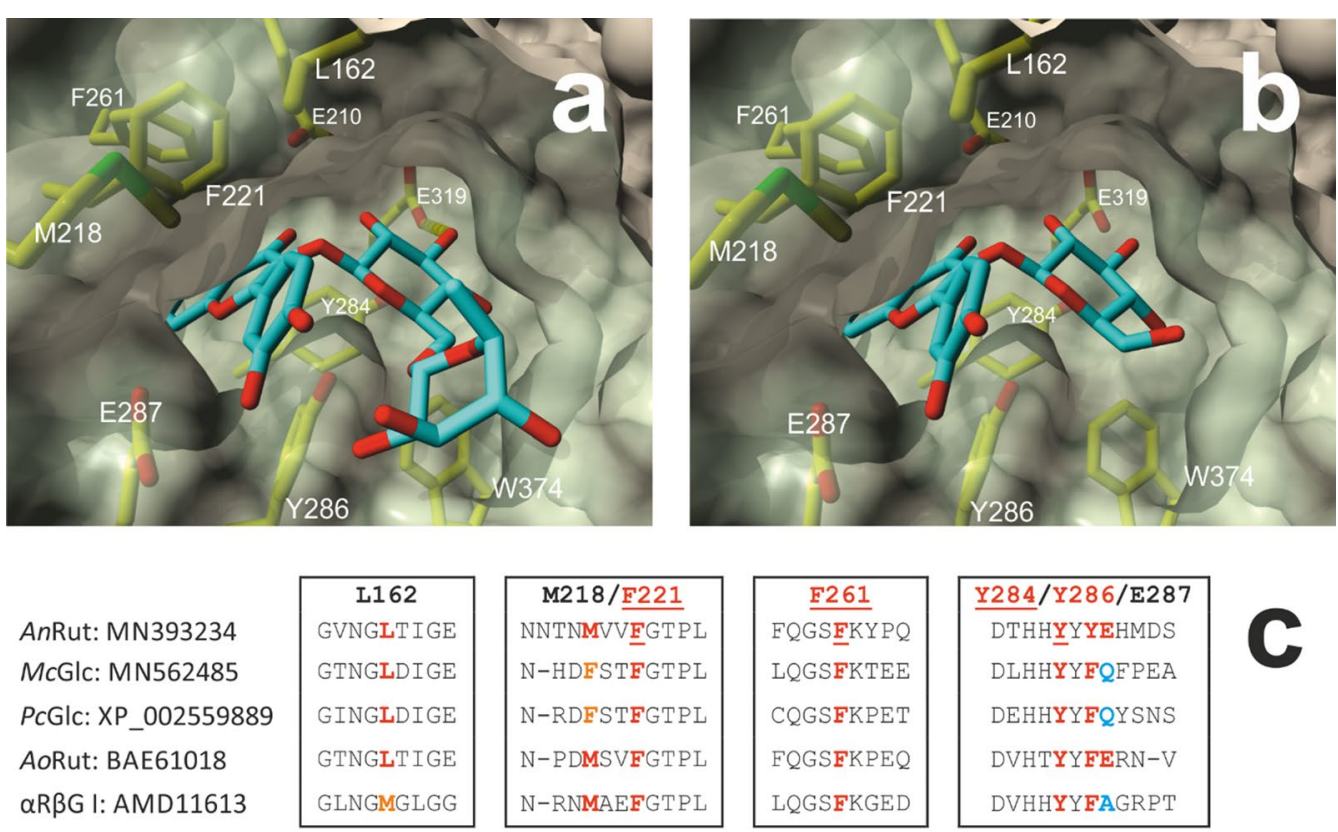

Fig. 2 View of the main entrance to the active site of AnRut with bound substrate $\mathbf{1}$ or $\mathbf{2}$ and multiple sequence alignment of GH5-23 member enzymes. a Molecular model of $\mathbf{2}$ docked to the active site with a free energy of binding of $-10.2 \mathrm{kcal} \mathrm{mol}^{-1}$. $\mathbf{b}$ Molecular model of docked $\mathbf{1}$ with a free energy of binding of $-9.3 \mathrm{kcal} \mathrm{mol}^{-1}$. Residues that interact with the bound substrates are labeled and shown in stick representation. These include in particular the aromatic sidechains of F221, F261, Y284 and Y286, which interact with the aglycones via many hydrophobic and $\pi-\pi$ interactions (Additional file 1: Tables S2-S5). In addition, hydrophobic interactions between the aglycones and the sidechains of L162, M218 and E287 were also found. The catalytic nucleophile E319 and the acid/base catalyst E210 are shown as well. The most favorable binding poses of $\mathbf{1}$ and $\mathbf{2}$ are shown. The double ring moiety of quercetin (rings A and C; see Fig. 1) is buried in the side tunnel and only incompletely visible. The above-mentioned residues were set flexible during the simulation. The AnRut-based residues are covered with a partially transparent molecular protein surface. c Multiple sequence alignment of GH5-23 member enzymes. Only segments around residues that-according to the molecular docking results - are involved in hydrophobic and $\pi-\pi$ interactions between the quercetin moiety of $\mathbf{1}$ or $\mathbf{2}$ and the +1 subsite of AnRut are shown. The aromatic residues F221, F261 and Y284 are fully conserved. The residues at the positions 162, 218 and 286 are partially conserved. The numbering refers to the sequence of AnRut (MN393234) (Pachl et al. 2020). The following sequences were aligned: MN562485 (McGlc) and XP_002559889 (PCGlc) (Kotik et al. 2021), BAE61018 (AoRut; Makabe et al. 2021), AMD11613 (aRßG l; Weiz et al. 2019)

The specific hydrolytic activities for the artificial substrate 9 were found markedly lower by a factor of $\sim 350$ compared with the corresponding data of 1 (Additional file 1: Table S6). Much lower activities were also determined for compound 10 in comparison with 2 for both $M c$ Glc and PcGlc. Moreover, the hydrolysis of $\mathbf{2}$ was virtually unaffected by the presence of $\beta$-D-glucose, $\alpha$-L-rhamnose and rutinose (Additional file 1: Table S6).

It is well known that secondary hydrolysis of reaction products results in lower product yields. Incubating $M c$ Glc or PcGlc with selected transglycosylation products revealed that virtually no hydrolysis was detectable by thin-layer chromatography (Additional file 1: Fig. S12). This outcome appears to be in line with the absence of a detectable inhibition of hydrolytic reactions with substrate 2 by moderate concentrations $(<12 \mathrm{mM})$ of transglycosylation product 6 (Additional file 1: Fig. S13).

\section{Transglycosylation reactions in solution}

In an attempt to compare the transglycosylation capabilities of $M c$ Glc and $P c$ Glc, various acceptors were tested in the presence of solubilized glycosyl donor $\mathbf{2}$ and $10 \%(\mathrm{v} / \mathrm{v})$ DMSO (Table 2). We did not detect any differences in acceptor preference between $\mathrm{McGlc}$ and $P c$ Glc, which underlines the high structural similarity of the enzymes. Interestingly, methanol, ethanol, pentan-2-ol, catechol and geraniol were rejected as acceptors, in contrast to AnRut. In an additional experiment, the total enzymatic activities in transglycosylations with 2-phenylethanol as a model acceptor and $\mathbf{1}$ or $\mathbf{2}$ as a glycosyl donor were compared between McGlc and PcGlc-mediated reactions (Fig. 4). For both enzymes and glycosyl donors, we observed the highest total activities at an acceptor concentration of $0.2-0.3 \mathrm{M}$. Concentrations exceeding $\sim 0.3 \mathrm{M}$ led to a decrease in overall activity, reaching different activity levels for PcGlc in the presence of $\mathbf{2}$ or $\mathbf{1}$. 


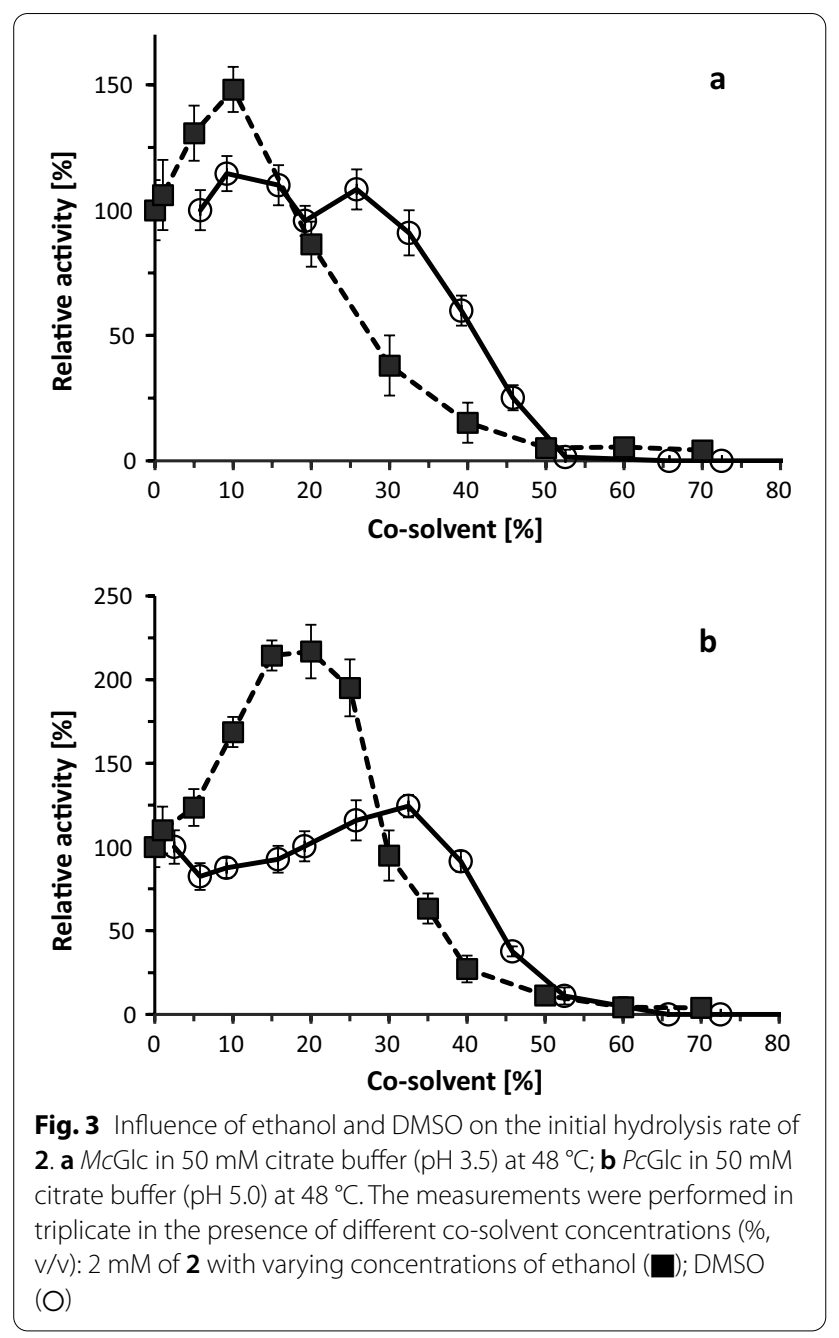

Table 1 Kinetic constants for the hydrolysis of compounds $\mathbf{1 - 4}$ using McGlc or PCGlc as a catalyst

\begin{tabular}{llll}
\hline Compound & Kinetic constants & McGlc & PcGlc \\
\hline $\mathbf{1}$ & $k_{\text {cat }}\left[\mathrm{s}^{-1}\right]$ & $53.9 \pm 1.9$ & $30.3 \pm 1.5$ \\
& $K_{\mathrm{M}}[\mathrm{mM}]$ & $0.04 \pm 0.01$ & $0.03 \pm 0.006$ \\
& $k_{\text {cat }} / \mathrm{K}_{\mathrm{M}}\left[\mathrm{s}^{-1} \mathrm{mM}^{-1}\right]$ & 1348 & 1010 \\
& $k_{\text {cat }}\left[\mathrm{s}^{-1}\right]$ & $22.7 \pm 0.5$ & $39.3 \pm 1.2$ \\
$\mathbf{2}$ & $K_{\mathrm{M}}[\mathrm{mM}]$ & $0.12 \pm 0.03$ & $0.21 \pm 0.06$ \\
& $k_{\text {cat }} / K_{\mathrm{M}}\left[\mathrm{s}^{-1} \mathrm{mM}^{-1}\right]$ & 189 & 187 \\
$\mathbf{3}$ & $k_{\text {cat }}\left[\mathrm{s}^{-1}\right]$ & $23.0 \pm 1.7$ & $9.3 \pm 0.8$ \\
& $K_{\mathrm{M}}[\mathrm{mM}]$ & $4.8 \pm 0.1$ & $0.38 \pm 0.09$ \\
& $k_{\text {cat }} / K_{M}\left[\mathrm{~s}^{-1} \mathrm{mM}^{-1}\right]$ & 4.8 & 24.5 \\
$\mathbf{4}$ & $k_{\text {cat }}\left[\mathrm{s}^{-1}\right]$ & $69.1 \pm 6.0$ & $120 \pm 13$ \\
& $K_{\mathrm{M}}[\mathrm{mM}]$ & $0.21 \pm 0.09$ & $0.29 \pm 0.1$ \\
& $k_{\text {cat }} / K_{M}\left[\mathrm{~s}^{-1} \mathrm{mM}^{-1}\right]$ & 257 & 414 \\
\hline
\end{tabular}

Table 2 Acceptor specificities for transglycosylation reactions with 2 as rutinosyl donor using McGlc or PcGlc as a catalystcomparison with AnRut ${ }^{\mathrm{b}}$

\begin{tabular}{lccc}
\hline Acceptor & McGlc & PcGlc & AnRut \\
\hline Methanol & $-{ }^{c}$ & - & + \\
Ethanol & - & - & + \\
$n$-Propanol & $+{ }^{d}$ & + & + \\
$n$-Butanol & + & + & + \\
Pentan-1-ol & + & + & n.d \\
Pentan-2-ol & - & - & + \\
Hexan-1-ol & + & + & n.d \\
Catechol & - & - & + \\
Geraniol & - & - & + \\
2-Phenylethanol & + & + & + \\
2-Azidoethanol & + & + & + \\
1,2-Hexanediol & + & + & n.d \\
3-Allyloxy-1,2-propanediol & + & + & n.d \\
Sodium azide & + & + & +
\end{tabular}

n.d. not determined

${ }^{a}$ Based on results obtained by thin-layer chromatography. Reaction conditions: $47^{\circ} \mathrm{C}, 1.8 \mathrm{mM} \mathrm{2}^{2} 0.12 \mathrm{\mu g} \mathrm{mL}^{-1}$ enzyme, $50 \mathrm{mM}$ citrate buffer at pH 4.0 (McGlc) or pH 5.0 (PcGlc), 10\% (v/v) DMSO

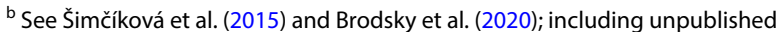
results

' No transglycosylation product detected

${ }^{\mathrm{d}}$ Transglycosylation product detected

e SeeKotik et al. (2021)

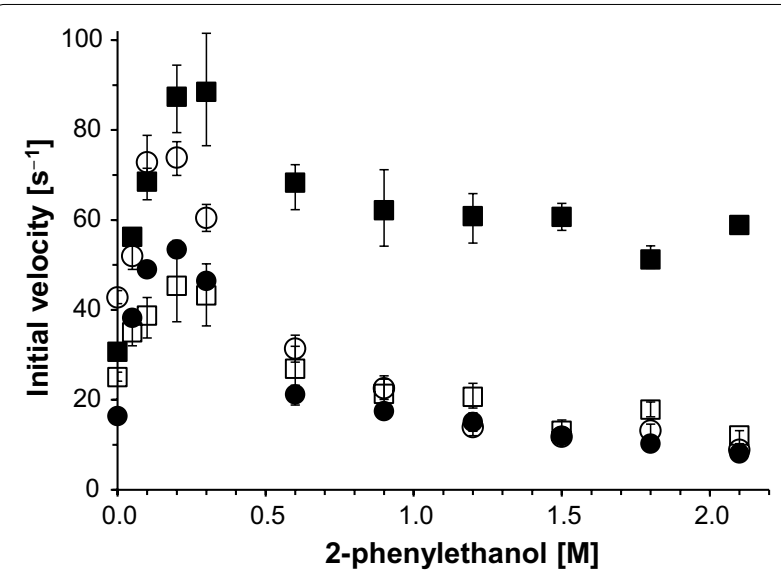

Fig. 4 Initial velocities of transglycosylation reactions with McGlc and PCGlc as catalysts in the presence of $\mathbf{1}$ or $\mathbf{2}$ and various concentrations of 2-phenylethanol. The total activities (hydrolysis plus transglycosylation) are shown for $\mathbf{1}$ (McGlc, O; PcGlc, $\square$ ) or $\mathbf{2}$ (McGlc,

- $P$ CGlc, $\square$ ) as a substrate/glycosyl donor. Reaction conditions: $37^{\circ} \mathrm{C}$, $10 \%$ DMSO, $1 \mathrm{mM}$ of compound $\mathbf{1}$ or $2 \mathrm{mM}$ of $\mathbf{2}, 0.25-1.0 \mu \mathrm{g} \mathrm{mL}{ }^{-1}$ of enzyme, $50 \mathrm{mM}$ citrate buffer at pH 4.0 (McGlc) or pH 5.0 (PcGlc) 
The transglycosylation performance of $\mathrm{McGlc}$ and PcGlc was further compared using 2-phenylethanol as an acceptor with $25 \%(\mathrm{v} / \mathrm{v})$ DMSO in the reaction mixture. The reaction conditions ensured full solubilization of glycosyl donor 2 at a concentration of $100 \mathrm{mM}$. Using an S/E ratio of $67^{\prime} 000 \mathrm{~mol} \mathrm{~mol}^{-1}$, the optimal acceptor concentration for the highest rutinoside production was determined to be 200 and $400 \mathrm{mM}$ for $M c$ Glc and $P c$ Glc, respectively (Additional file 1: Fig. S14). Regarding yield, $P c$ Glc exhibited a slightly better performance with a maximum yield of $49 \%$ for synthesized 6 (based on the initial concentration of 2) in comparison with $M c$ Glc with a maximum yield of $43 \%$. The reaction time courses are shown in Additional file 1: Fig. S15. The PcGlc-based transglycosylation yields were found independent of the S/E ratio in the range of $20^{\prime} 000$ to $67^{\prime} 000 \mathrm{~mol} \mathrm{~mol}^{-1}$. A lower transglycosylation yield of $28 \%$ for $M c$ Glc in the presence of $400 \mathrm{mM}$ acceptor was improved to $40 \%$ by augmenting the enzyme load (i.e., reducing the S/E ratio from $67^{\prime} 000$ to $20^{\prime} 000 \mathrm{~mol} \mathrm{~mol}^{-1}$ ) (Additional file 1: Fig. S16). The calculated process parameters for low and high conversions of $\mathbf{2}$ are listed for the optimized transglycosylation reactions in Table 3.

\section{Hydrolysis in suspensions}

The performance of $M c$ Glc and PcGlc was further analyzed for hydrolytic reactions with mostly undissolved 2 at a concentration of $185 \mathrm{~g} \mathrm{~L}^{-1}(0.3 \mathrm{M})$ in the absence of a co-solvent. Although the reaction mixtures were thick suspensions, complete conversions were observed for both enzymes (Additional file 1: Fig. S17). Turnover frequency (TOF) values of $\sim 13^{\prime} 000 \mathrm{~h}^{-1}$ for the first hour of the 16-h long processes were determined for both $\mathrm{McGlc}$ and PcGlc-based conversions. A summary of the performance metrics of the hydrolytic processes is shown in Table 4. It should be noted that one of the reaction products, quercetin, is virtually insoluble in water, consequently, as the reaction proceeded, the mixture remained in a state of a slurry (Kapešová et al. 2019).

\section{Transglycosylations in suspensions}

Before we embarked on the optimization of the transglycosylation reactions under heterogeneous conditions with $\mathbf{2}$ as the glycosyl donor, we performed not optimized reactions using either catalyst and 2-phenylethanol or rac-1,2-hexanediol as an acceptor. Two reactions were performed on a $15-\mathrm{ml}$ scale using the combinations $M c$ Glc/2-phenylethanol and PcGlc/1,2-hexanediol (Additional file 1: Fig. S18). The reaction products were isolated and subsequently characterized by mass and NMR

Table 3 Performance of McGlc and PCGlc in optimized transglycosylation reactions at low and high conversions with dissolved $\mathbf{2}$ and 2-phenylethanol ${ }^{\mathrm{a}}$

\begin{tabular}{|c|c|c|c|c|c|c|}
\hline & \multicolumn{2}{|c|}{ TOF $^{c}$} & \multicolumn{2}{|c|}{ Productivity $^{d}$} & \multicolumn{2}{|c|}{ STYe } \\
\hline$x^{b}$ & 0.2 & 0.7 & 0.2 & 0.7 & 0.2 & 0.7 \\
\hline McGlc & 13 & 6.9 & 1240 & 640 & 86 & 44 \\
\hline PCGlc & 8.9 & 2.9 & 901 & 292 & 57 & 19 \\
\hline
\end{tabular}

a Using a substrate to enzyme (S/E) ratio of $67,000 \mathrm{~mol} \mathrm{~mol}^{-1}$. Reaction conditions: $35^{\circ} \mathrm{C}, 25 \%$ (v/v) DMSO, $100 \mathrm{mM}$ initial concentration of 2; 200 or $397 \mathrm{mM}$ of 2-phenylethanol for McGlc or PcGlc-based reactions, respectively. The quantification of quercetin and compound 6 enabled the determination of the total (i.e., hydrolysis and transglycosylation) and the transglycosylation-specific conversion, respectively

${ }^{\mathrm{b}} \mathrm{X}$ : conversion of glycosyl donor 2

'Turnover frequency: $10^{4} \mathrm{~mol}$ of $\mathbf{6} \cdot(\text { mole of catalyst } \cdot h)^{-1}$

${ }^{\mathrm{d}}$ Catalyst productivity: $\mathrm{g}$ of $\mathbf{6} \cdot(\mathrm{g} \text { catalyst } \cdot \mathrm{h})^{-1}$

e Space-time yield: $g$ of $6 \cdot(L \cdot h)^{-1}$

Table 4 Performance of McGlc and PCGlc in hydrolysis reactions at low and high conversions with $\mathbf{2}$ in suspension ${ }^{\mathrm{a}}$

\begin{tabular}{|c|c|c|c|c|c|c|}
\hline & \multicolumn{2}{|c|}{ TOF $^{\mathrm{c}}$} & \multicolumn{2}{|c|}{ Productivity $^{d}$} & \multicolumn{2}{|c|}{ STY } \\
\hline$x^{b}$ & 0.2 & 0.7 & 0.2 & 0.7 & 0.2 & 0.7 \\
\hline McGlc & 1.7 & 0.7 & 108 & 45 & 36 & 15 \\
\hline PCGlc & 1.5 & 0.6 & 108 & 45 & 36 & 15 \\
\hline
\end{tabular}

a Using an S/E ratio of $40^{\prime} 000 \mathrm{~mol} \mathrm{~mol}^{-1} ; 35^{\circ} \mathrm{C}$; initial concentration of 2: $300 \mathrm{mM}$

${ }^{\mathrm{b}} \mathrm{X}$ : conversion of substrate $\mathbf{2}$

'Turnover frequency: $10^{4} \mathrm{~mol}$ of quercetin.(mole of catalyst.h $)^{-1}$

${ }^{d}$ Catalyst productivity: $g$ of quercetin $\cdot(g \text { catalyst } \cdot h)^{-1}$

e Space-time yield: $g$ of quercetin. $(L \cdot h)^{-1}$ 
spectrometry (compound 6: Additional file 1: Table S7 and Fig. S19-S21; compounds 7/8: Additional file 1: Tables S8 and S9, Fig. S22-S24). The acquired data were congruous with the expected structures of 6 and $7 / 8$. The configuration at the anomeric centers was determined to be beta as inferred from the $\mathrm{H}-1 / \mathrm{H}-2$ coupling constants $\left(J_{\mathrm{H} 1, \mathrm{H} 2}=7.9-8.0 \mathrm{~Hz}\right.$; Additional file 1: Tables S7-S9). The connection between the monosaccharide unit and the aglycone was confirmed using corresponding HMBC correlations. In the presence of rac-1,2-hexanediol two pairs of epimers were produced with the glycosidic bond linked either to the methylene bridge (compound 7) or to the methanetriyl group (compound 8). Compounds $7 / 8$ were isolated as a mixture of two pairs of epimers with compound 7 in a 2.3-fold excess over compound 8 as determined by NMR analysis (Additional file 1: Table S8).

Next, we undertook a detailed comparison between the transglycosylation capabilities of $\mathrm{McGlc}$ and PcGlc with 2-phenylethanol as a model acceptor compound. The reaction mixtures contained $185 \mathrm{~g} \mathrm{~L}^{-1}(0.3 \mathrm{M})$ of 2 as a glycosyl donor, forming a slurry. In a first attempt, the enzyme load was tested. It turned out that the maximal transglycosylation yield was independent of the S/E ratio between $15^{\prime} 000$ to $55^{\prime} 000 \mathrm{~mol} \mathrm{~mol}^{-1}$ for both enzymes. Next, the correlation between acceptor concentration and rutinoside formation was studied. Using $M c$ Glc as a catalyst, the data indicated a slightly higher relative conversion towards the transglycosylation product $\mathbf{6}$ at high acceptor concentrations $(\sim 1.5 \mathrm{M})$ in comparison with the total conversion (Additional file 1: Fig. S25). In the case of $P c$ Glc, a rather sharp increase of the conversion of 2 with the acceptor concentration was followed by a moderate increase in both total and transglycosylationlinked conversions (Additional file 1: Fig. S26). As a next step, a time course experiment, in which we followed the production of quercetin and the transglycosylation product 6, was performed with a common S/E ratio of $55^{\prime} 000 \mathrm{~mol} \mathrm{~mol}^{-1}$. Based on the previous experiments, optimal acceptor concentrations of 1.5 and $1.2 \mathrm{M}$ were selected for the McGlc and PcGlc-mediated reactions, respectively (Additional file 1: Fig. S27). The reaction efficiencies for both processes are summarized in Table 5 for low and high conversions. Both reactions reached a plateau $8 \mathrm{~h}$ after the initiation of the reaction. Higher yields of 97 and $25 \%$ for quercetin and product 6 were determined for the PcGlc-mediated process, compared with the $M c$ Glc-based reaction with 75 and 20\%, respectively.

\section{Discussion \\ Substrate specificities}

As part of the assessment of McGlc and PcGlc for biotechnological applications, which included two different enzyme purification strategies, we first determined the substrate specificities of these enzymes. From these data we can conclude that-(1) small structural variations in the aglycone have a profound influence on the enzyme activity (see $\mathbf{2}$ versus 4 or $\mathbf{3}$ versus 5), (2) the specificity of $M c$ Glc and PcGlc towards the type of linkage between the two glycone units is very high $(1 \rightarrow 6$ versus $1 \rightarrow 2$ glycosidic linkage; see 3 versus 11), (3) McGlc and PcGlc appear to prefer flavonoid rutinosides with 3-O-linkages over rutinosides with 7-O-linkages (see 4 versus 5 and 2 versus 3 ), and (4) the presence of a terminal rhamnosyl residue as in compound 2 leads to a lower $k_{\text {cat }}$ value and a higher $K_{\mathrm{M}}$ value compared to compound $\mathbf{1}$, which lacks the rhamnosyl residue but contains the same aglycone moiety. The presence of a double bond in the heterocyclic ring of 5 (compared to 3 ) had a striking effect on the steady-state kinetics of both enzymes; they exhibited an extreme level of what appeared to be substrate inhibition (Additional file 1: Fig. S7). Both $M c$ Glc and PcGlc were shown to be most active with the flavonoid glucoside 1, as found for AnRut (Pachl et al. 2020). High activity towards $\mathbf{1}$ was also determined for the rutinosidase from Aspergillus oryzae (Makabe et al. 2021).

Table 5 Performance of McGlc and PCGlc in optimized transglycosylation reactions at low and high conversions with $\mathbf{2}$ in suspension in the presence of 2-phenylethanol ${ }^{a}$

\begin{tabular}{|c|c|c|c|c|c|c|}
\hline \multirow[b]{2}{*}{$x^{b}$} & \multicolumn{2}{|l|}{ TOF $^{\mathrm{C}}$} & \multicolumn{2}{|c|}{ Productivity $^{d}$} & \multicolumn{2}{|l|}{ STYe } \\
\hline & 0.2 & 0.7 & 0.2 & 0.7 & 0.2 & 0.7 \\
\hline McGlc & $2.1(6.1)$ & $0.14(0.6)$ & $174(353)$ & $11(32)$ & $50(101)$ & $3.2(9)$ \\
\hline PcGlc & $1.2(3.6)$ & $0.51(1.9)$ & $135(284)$ & 57 (149) & $29(61)$ & $12(32)$ \\
\hline
\end{tabular}

a Using an S/E ratio of $55^{\prime} 000 \mathrm{~mol} \mathrm{~mol}^{-1} ; 35^{\circ} \mathrm{C}$; initial concentration of $2: 300 \mathrm{mM}$. The quantification of quercetin and compound 6 enabled the determination of the total (i.e., hydrolysis and transglycosylation) and the transglycosylation-specific conversion, respectively. The data in parentheses were calculated based on quercetin as the reaction product

${ }^{\mathrm{b}} \mathrm{X}$ : conversion of glycosyl donor 2

'Turnover frequency: $10^{4} \mathrm{~mol}$ of $\mathbf{6}$ or quercetin.(mole of catalyst.h) ${ }^{-1}$

${ }^{d}$ Catalyst productivity: $g$ of $\mathbf{6}$ or quercetin. $(\mathrm{g} \text { catalyst } \cdot \mathrm{h})^{-1}$

e Space-time yield: $g$ of $\mathbf{6}$ or quercetin.(L.h $)^{-1}$ 


\section{Interactions between aglycone and +1 subsite}

Based on the above-mentioned data we can conclude that the hydrophobic and $\pi-\pi$ interactions between the aromatic side chains in the +1 subsite of GH5-23 glycosidases and the aglycone of the substrate/glycosyl donor are highly important for binding and fast conversions. The conclusion is supported by: $(i)$ the molecular docking results of the in silico binding of $\mathbf{1}$ and $\mathbf{2}$ to the $A n$ Rut active site together with the multiple sequence alignment of GH5-23 glycosidases and their conserved aromatic residues in the inferred +1 subsite, $(i i)$ the very low hydrolytic activities with the substrates 9 and 10, (iii) the virtual absence of secondary hydrolysis of the transglycosylation products, and (iv) the fact that moderate concentrations of $\mathbf{6}$, glucose, rhamnose or rutinose did not substantially affect the initial hydrolysis rate of compound 2. In conclusion, substrates and glycosyl donors that lack the aromatic three-ring aglycone structure of compounds 1-4 are not congruous with high conversion rates.

\section{Transglycosylation in solution}

In accordance with the determined beta configuration at the anomeric centers of the reaction products 6 and $7 / 8$, we concluded that $M c$ Glc and $P c$ Glc function as retaining glycosidases. The increase in the total activity in the presence of 1 or $\mathbf{2}$ and intermediate 2-phenylethanol concentrations compared with the activity in the absence of the acceptor may have different causes. The nucleophilicity of the active site nucleophile may get stronger in the presence of co-solvents as a result of less intense water solvation of the nucleophile (see Fig. 3 for a similar effect caused by ethanol; Kudryashova et al. 2003). We may also speculate that the rate-limiting step in the transglycosylation reaction pathway is the hydrolysis of the glycosylenzyme intermediate (deglycosylation step) and not its formation. In such a case, the addition of 2-phenylethanol as an acceptor to the reaction mixture would increase the total reaction rate as previously observed with inorganic azide (Additional file 1: Fig. S28; Kotik et al. 2021). This appears to be true for both $\mathbf{1}$ and $\mathbf{2}$ as substrates/ glycosyl donors. Our conclusions are also based on the well-established data of the serine protease chymotrypsin (Fersht 1985), whose reaction mechanism resembles the mechanism of retaining glycosidases in several aspects, including the presence of a covalent intermediate. Acceptor concentrations exceeding $\sim 0.3 \mathrm{M}$ led to a decrease in overall activity, possibly due to adverse conformational effects or inhibition caused by two or more acceptor molecules bound to the active site. Concerning the regioselectivity of $P c$ Glc, 1,2-hexanediol was preferentially rutinosylated at the primary hydroxyl group with a selectivity of $\sim 70 \%$. Similar data were reported for 1,2 -propanediol with a number of $\beta$-glycosidases (van Rantwijk et al. 1999).

\section{Reactions in solution versus in suspension}

Compound 2 has a very low water solubility of $125 \mathrm{mg}$ $\mathrm{L}^{-1}$ (Frutos et al. 2019). Hence, co-solvents such as DMSO help solubilize 2 and usually ensure faster conversions if catalyst denaturation can be avoided. Indeed, one of the advantageous features of $M c$ Glc and $P c$ Glc is their high resistance against DMSO and ethanol-induced inactivation in comparison with, e.g., AnRut with its substantial proneness to activity loss in the presence of these co-solvents (Šimćíková et al. 2015). Therefore, $M c$ Glc and PcGlc offer the possibility to perform transglycosylations with dissolved $\mathbf{2}$ at a high concentration of $100 \mathrm{mM}$, which are conditions that led to double yields of 6 and much better productivities and TOF values in comparison with the 'solid-state' approach (Tables 3 and 5). A potential drawback of DMSO in the reaction mixture may lie in the interference with product work-up. However, the efficient removal of DMSO is possible using solid-state extraction (Crawford et al. 2018). Lyophilization is another option; due to the low vapor pressure of DMSO, it is probably not the preferred method (Müller et al. 2019). Regarding the TOF numbers, both transglycosylation approaches can be considered potentially economical for high-value products (Behr and Neubert 2012). However, the lower yield of 6 for the 'solid-state' process is a considerable disadvantage in comparison with the solution-based reaction. The presence of 2-phenylethanol considerably improved the hydrolysis of $\mathbf{2}$ under heterogeneous reaction conditions (Tables 4 and 5). It is very likely that this effect has to be attributed to a better solubilization and thus an improved availability of 2 as a result of 2-phenylethanol (1.2-1.5 M) that acts both as an aglycone and co-solvent.

The yields of transglycosylation reactions depend on many factors, including the type of the acceptor, the biocatalyst, the acceptor-to-donor ratio, and the cosolvent used (Zeuner et al. 2019). Typically, several reaction parameters have to be optimized to achieve the highest conversion (Guo et al. 2015; Manas et al. 2018; Mazzaferro et al. 2019). Acceptors compete with water during the deglycosylation step of the two-step displacement mechanism of retaining glycosidases (Bissaro et al. 2015). The outcome of this competition in the attack on the covalent glycosyl-enzyme intermediate with its complex interactions determines the transglycosylation to hydrolysis ratio. Notably, optimizations of transglycosylation reactions have their limits, as shown by the fact that transglycosylation yields of more than 50\% have rarely been reported (Desmet et al. 2012; 
Guo et al. 2015) - with the exception of reactions using transglycosidases (Bissaro et al. 2015).

In this study, we focused on the biotechnological potential of two flavonoid-specific glucosidases/rutinosidases, McGlc and PcGlc. The biochemical characterization of the two GH5-23 family members revealed enzyme characteristics that are highly advantageous for biotransformation reactions. In particular, significant stabilities against thermal and DMSO-induced inactivation, acceptance of both flavonoid glucosides and rutinosides as substrates, transglycosylation capabilities with a considerable number of acceptors, and a very limited secondary hydrolysis of the formed transglycosylation products should be mentioned. Very similar efficiencies for the hydrolysis of $\mathbf{2}$ at a concentration of $0.3 \mathrm{M}$ were determined for $\mathrm{McGlc}$ and PcGlc. In terms of yields, PcGlc outperformed McGlc in optimized transglycosylation reactions for the synthesis of compound $\mathbf{6}$ with $\mathbf{2}$ as a glycosyl donor under both homogeneous and heterogeneous reaction conditions. The rutinosylation of 2-phenylethanol in the presence of $25 \%$ DMSO was demonstrated to lead to much higher efficiencies and double yields of $\mathbf{6}$ in comparison with the corresponding transglycosylation reactions performed in 'solid-state' mode. Molecular docking and multiple sequence alignments point towards hydrophobic and $\pi-\pi$ interactions between the flavonoid aglycone and the aromatic residues in the +1 subsite as a major driving force for substrate recognition.

\section{Supplementary Information}

The online version contains supplementary material available at https://doi. org/10.1186/s13568-021-01298-2.

Additional file 1. Additional figures and tables.

\section{Acknowledgements}

We thank Dr. Lucie Petrásková (Institute of Microbiology of the Czech Academy of Sciences) for performing the mass spectrometry analyses.

\section{Authors' contributions}

$\mathrm{HJ}$ and KB conducted the experiments and analyzed data. HP performed the NMR experiments. MK conceived the experiments and wrote the manuscript. All authors read and approved the final manuscript.

\section{Funding}

The work was supported by the Czech Science Foundation (Grant No. 19-00091S).

\section{Availability of data and materials}

The authors confirm that the data supporting the findings of this study can be found in the article and its supplementary material.

\section{Declarations}

Ethics approval and consent to participate

Not applicable: this study does not contain any studies with human participants or animals.
Consent for publication

All authors have approved the manuscript for publication.

\section{Competing interests}

The authors declare no competing interests.

\section{Author details}

${ }^{1}$ Institute of Microbiology of the Czech Academy of Sciences, Vídeňská 1083, 14220 Prague 4, Czech Republic. Department of Biochemistry and Microbiology, University of Chemistry and Technology Prague, Technická 3, 16628 Prague 6, Czech Republic.

Received: 5 October 2021 Accepted: 11 October 2021

Published online: 18 October 2021

\section{References}

Baglioni M, Breccia JD, Mazzaferro LS (2021) Peculiarities and systematics of microbial diglycosidases, and their applications in food technology. Appl Microbiol Biotechnol 105:2693-2700

Behr A, Neubert P (2012) Applied Homogeneous Catalysis. Wiley-VCH Verlag, Weinheim, Germany

Benkert P, Biasini M, Schwede T (2011) Toward the estimation of the absolute quality of individual protein structure models. Bioinformatics 27:343-350

Bissaro B, Monsan P, Fauré R, O'Donohue MJ (2015) Glycosynthesis in a waterworld: new insight into the molecular basis of transglycosylation in retaining glycoside hydrolases. Biochem J 467:17-35

Brodsky K, Kutý M, Pelantová H, Cvačka J, Rebroš M, Kotik M, Kutá Smatanová I, Křen V, Bojarová P (2020) Dual substrate specificity of the rutinosidase from Aspergillus niger and the role of its substrate tunnel. Int J Mol Sci 21:5671

Crawford LM, Holstegeb DM, Wang SC (2018) High-throughput extraction method for phenolic compounds in olive fruit (Olea europaea). Food Compos Anal 66:136-144

Desmet T, Soetaert W, Bojarová P, Křen V, Dijkhuizen L, Eastwick-Field V, Schiller A (2012) Enzymatic glycosylation of small molecules: challenging substrates require tailored catalysts. Chem Eur J 18:10786-10801

Fersht A (1985) Enzyme structure and mechanism, 2nd edn. W. H. Freeman and Company, New York, USA

Frutos MJ, Rincón-Frutos L, Valero-Cases E (2019) Rutin. In: Nabavi SM, Silva AS (eds) Nonvitamin and Nonmineral Nutritional Supplements. Elsevier, Academic Press, pp 111-117

Gullon B, Lú-Chau TA, Moreira MT, Lema JM, Eibes G (2017) Rutin: a review on extraction, identification and purification methods, biological activities and approaches to enhance its bioavailability. Trends Food Sci Technol 67:220-235

Guo Y, Yan Q, Yang Y, Yang S, Liu Y, Jiang Z (2015) Expression and characterization of a novel $\beta$-glucosidase, with transglycosylation and exo- $\beta-1,3-$ glucanase activities, from Rhizomucor miehei. Food Chem 175:431-438

Kapešová J, Petrásková L, Markošová K, Rebroš M, Kotik M, Bojarová P, Křen V (2019) Bioproduction of quercetin and rutinose catalyzed by rutinosidase: novel concept of "solid state biocatalysis." Int J Mol Sci 20:1112

Karnišová Potocká E, Mastihubová M, Mastihuba V (2021) Transrutinosylation of tyrosol by flower buds of Sophora japonica. Food Chem 336:127674

Katayama S, Ohno F, Yamauchi Y, Kato M, Makabe H, Nakamura S (2013) Enzymatic synthesis of novel phenol acid rutinosides using rutinase and their antiviral activity in vitro. J Agric Food Chem 61:6917-9622

Kiso A, Oto N, Nakahara T, Yasuda T, Zhou YY, Shu E (2015) Japanese Patent Application No. JP5667774-B2

Koseki T, Ishikawa M, Kawasaki M, Shiono Y (2018) $\beta$-Diglycosidases from microorganisms as industrial biocatalysts: biochemical characteristics and potential applications. Appl Microbiol Biotechnol 102:8717-8723

Kotik M, Brodsky K, Halada P, Javůrková H, Pelantová H, Konvalinková D, Bojarová P, Křen V (2021) Access to both anomers of rutinosyl azide using wild-type rutinosidase and its catalytic nucleophile mutant. Catal Commun 149:106193

Krieger E, Vriend G (2014) YASARA view_molecular graphics for all devicesfrom smartphones to workstations. Bioinformatics 30:2981-2982

Kudryashova EV, Artemova TM, Vinogradov AA, Gladilin AK, Mozhaev V, Levashov AV (2003) Stabilization and activation of a-chymotrypsin in 
water-organic solvent systems by complex formation with oligoamines. Protein Eng 16:303-309

Lucci N, Mazzafera P (2009) Distribution of rutin in fava d'anta (Dimorphandra mollis) seedlings under stress. J Plant Interact 4:203-208

Makabe K, Hirota R, Shiono Y, Tanaka Y, Koseki T (2021) Aspergillus oryzae rutinosidase: biochemical and structural investigation. Appl Environ Microbiol 87:e02438-e2520

Manas NHA, Illias RM, Mahadi NM (2018) Strategy in manipulating transglycosylation activity of glycosyl hydrolase for oligosaccharide production. Crit Rev Biotechnol 38:272-293

Mazzaferro LS, Weiz G, Braun L, Kotik M, Pelantová H, Křen V, Breccia JD (2019) Enzyme-mediated transglycosylation of rutinose (6-O-a-L-rhamnosyl-Dglucose) to phenolic compounds by a diglycosidase from Acremonium sp. DSM 24697. Biotechnol Appl Biochem 66:53-59

Müller C, Wagner AL, Rockinger U, Winter G, Bracher F (2019) Development of a convenient method for the determination of dimethyl sulfoxide in lyophilised pharmaceuticals by static headspace gas chromatographymass spectrometry. Anal Methods 16:2119-2122

O'Shea N, Arendt EK, Gallagher E (2012) Dietary fibre and phytochemical characteristics of fruit and vegetable by-products and their recent applications as novel ingredients in food products. Innov Food Sci Emerg Technol 16:1-10

Pachl P, Kapešová J, Brynda J, Biedermannová L, Pelantová H, Bojarová P, Křen V, Řezáčová P, Kotik M (2020) Rutinosidase from Aspergillus niger: crystal structure and insight into the enzymatic activity. FEBS J 287:3315-3327

Rather MY, Mishra S (2013) $\beta$-Glycosidases: An alternative enzyme based method for synthesis of alkyl-glycosides. Sustain Chem Process 1:7

Sheldon RA (2016) Biocatalysis and green chemistry. In: Patel RN (ed) Green Biocatalysis. Wiley, Hoboken, New Jersey, pp 1-15

Šimčíková D, Kotik M, Weignerová L, Halada P, Pelantová H, Adamcová K, Křen $\checkmark$ (2015) a-L-Rhamnosyl-B-D-glucosidase (rutinosidase) from Aspergillus niger: characterization and synthetic potential of a novel diglycosidase. Adv Synth Catal 357:107-117

Slámová K, Kapešová J, Valentová K (2018) "Sweet flavonoids": glycosidasecatalyzed modifications. Int J Mol Sci 19:2126

Testai L, Calderone V (2017) Nutraceutical value of citrus flavanones and their implications in cardiovascular disease. Nutrients 9:502
Thompson JD, Higgins DG, Gibson TJ (1994) CLUSTAL W: improving the sensitivity of progressive multiple sequence alignment through sequence weighting, position-specific gap penalties and weight matrix choice. Nucleic Acids Res 22:4673-4680

Trott O, Olson AJ (2010) AutoDock VINA: improving the speed and accuracy of docking with a new scoring function, efficient optimization and multithreading. J Comput Chem 31:455-461

Van Rantwijk F, Woudenberg-van Oosterom M, Bhagwat SA, Dwyer JT, Gebhardt SE, Haytowitz DB, Sheldon RA (1999) Glycosidase-catalyzed synthesis of alkyl glycosides. J Mol Catal b: Enzym 6:511-532

Waterhouse A, Bertoni M, Bienert S, Studer G, Tauriello G, Gumienny R, Heer TF, de Beer TAP, Rempfer C, Bordoli L, Lepore R, Schwede T (2018) SWISSMODEL: homology modelling of protein structures and complexes. Nucleic Acids Res 46:W296-W303

Weignerová L, Marhol P, Gerstorferová D, Křen V (2012) Preparatory production of quercetin-3- $\beta$-D-glucopyranoside using alkali-tolerant thermostable a-L-rhamnosidase from Aspergillus terreus. Bioresour Technol 115:222-227

Weiz G, Mazzaferro LS, Kotik M, Neher BD, Halada P, Křen V, Breccia JD (2019) The flavonoid degrading fungus Acremonium sp. DSM 24697 produces two diglycosidases with different specificities. Appl Microbiol Biotechnol 103:9493-9504

Williamson G (2017) The role of polyphenols in modern nutrition. Nutr Bull 42:226-235

Zeuner B, Teze D, Muschiol J, Meyer AS (2019) Synthesis of human milk oligosaccharides: protein engineering strategies for improved enzymatic transglycosylation. Molecules 24:2033

Zhang D, Du M, Wei Y, Wang C, Shen L (2018) A review on the structure-activity relationship of dietary flavonoids for protecting vascular endothelial function: current understanding and future issues. J Food Biochem 42:e12557

\section{Publisher's Note}

Springer Nature remains neutral with regard to jurisdictional claims in published maps and institutional affiliations.

\section{Submit your manuscript to a SpringerOpen ${ }^{\circ}$ journal and benefit from:}

- Convenient online submission

- Rigorous peer review

- Open access: articles freely available online

- High visibility within the field

- Retaining the copyright to your article

Submit your next manuscript at $\boldsymbol{\nabla}$ springeropen.com 